\title{
TERTIARY EDUCATION: MEETING STAKEHOLDER EXPECTATIONS IN A FAST-CHANGING WORLD
}

\author{
Kathiravelu Ganeshan and Farhad Mehdipour
}

\section{INTRODUCTION}

This article is in three parts. In the first part, the first author documents operational details of a proven method of successfully meeting, and exceeding, the expectations of the stakeholders in the tertiary education sector. In addition, the first author discusses more efficient and effective ways of writing meaningful assessments, marking and moderating, than the ones in current use in many New Zealand tertiary institutions.

In the second part, the second author gives his perspective on the facilitation of learning at Otago Polytechnic Auckland International Campus (OPAIC).

In the third part, the authors, both now working at OPAIC, discuss how they are merging the best practices, and the results.

\section{PART I: AUTHOR I}

I have been in academia for a very long time. I started my teaching career using chalk and talk, giving two-hour lectures, and writing and marking written theory examinations. As the years passed, I stepped through overhead projector transparencies, whiteboards, Kodak slide projectors, 3-gun CRT projectors, LCD projectors, and of course, PowerPoint slides and Prezi.

I have taught courses from Level 4 to Level 9. I have taught some courses that used Unit Standards. I had short stints in a community college, with my oldest learner in their nineties, and at secondary school, and coached people in badminton, bridge, sailing and swimming. The major part of my career in education, however, was as a lecturer in degree programmes at universities and polytechnics - lectures, tutorials, exams, projects, and theses supervision, marking and moderation.

More than ten years ago, I ditched Bloom's Taxonomy and stopped teaching. In most cases, I also found a way to avoid giving written theory exams, and I stopped using Turnitin. My learners shifted their focus from passing exams and grades, to authentic learning. All of them enjoyed learning; very few attempted to cheat; the ones who tried to cheat, got caught.

Staff in my department enjoyed being part of the team. They did not have to spend countless hours preparing slides, giving lectures, writing long assessments, marking scripts, preparing and submitting evidence for moderation, and moderating.

In the next few sections, I describe how we did this, why almost everyone enjoys this way of doing things, and why this produces socially-responsive, life-long learners capable of adapting to a fast-changing world. I also discuss why Turnitin is just a waste of time and money, and why the number of learners who tried to cheat was tiny, and how those who tried to cheat got caught. 


\section{Content is Everywhere}

We are living in an era in which anyone can learn almost anything as long as they have access to a laptop, tablet or a phone, and access to the internet. Many people, including myself, have learnt practical skills, like swimming and catching green waves, from the internet. The world's best universities, and others are continuing to add to the huge collection of online learning resources. Learners do not pay fees for this content.

\section{Letting go of Our Ego}

Given that there is so much content out there, for free, and at the swipe of a finger, a mouse click or a simple voice command to Alexa, we need to consciously break the shackles that we put on ourselves and surrender our content-provider status. When we let go of our ego and "status", we open our minds to the idea that there is so much content out there, that we can all learn and continue to learn, to come up with new ideas and use these ideas to find better ways of doing things. Without limitation, learning becomes an enjoyable, meaningful activity.

\section{Recruiting New Learners by telling them that we do not give Lectures}

In my role as a head of department, my first encounter with potential learners living overseas was often a Skype video interview. During these interviews, I always told them that in our department we gave no lectures nor had any written theory examinations. Their first reaction was always one of disbelief. I would spend a few minutes explaining to them what we did, and then I would carry my laptop around to the different classrooms to show what our current learners were doing. More often than not I would ask one or more current learners to speak with the prospective learners in their first language and I would leave the room: we had so much confidence that our current learners would sing the praises of, and recommend our way of facilitating learning, and the institution. We know they enjoyed being part of the institution, had fun learning, and were making progress at their own pace, in a highly collaborative environment - so, why would they tell a potential learner not to join the institution?

\section{Orientation I: Institution Level}

During the orientation at the institution level, I would say very little about my department and spend more time telling all learners about water safety and the dangers of New Zealand's west coast beaches, Hot Water Beach, and rip currents. Learners from other departments had even seen my YouTube swimming and windsurfing videos while they were still in their home countries including Russia and India, while trying to choose an institution in New Zealand.

\section{Orientation 2: Department Level}

On their first day at college, new learners joined the previous cohort in the same classroom. A carousel system of intakes and deliberate planning of course offerings made it possible to have each cohort join the previous cohort in the same course - later on, you will see why this is so important.

Departmental orientation took place on the afternoon of the first day of the term and had three parts. The first part consisted of introductions and getting to know the sporting, cooking, baking, travel and other interests of learners and staff. The second part introduced the concepts of collaborative knowledge building, waka, and whānau. During the third part, new learners observed learners from the previous cohorts present and defend the projects they completed in the previous term. New learners were also encouraged to ask questions during the defence.

These presentations by learners from the previous cohort, who had only been in the programme for just eight weeks, and the quality of the projects and the confidence with which they presented and answered questions helped new learners see what they were expected to, and could achieve in just eight weeks. 


\section{Striking the Iron While it is Hot}

Now that the new learners know that New Zealand's west coast beaches have rip currents and it is good to know about rip currents, how to avoid getting caught in one and what to do if they are caught, and also know what the previous cohort was able to achieve in eight weeks, it is time to talk about how we learn without lectures. Remember, most of them already may know that we did things differently, with some even choosing the institution because of the difference (no boring lectures and no written theory exams), it is still a difficult concept to accept.

The new learners witnessing a happy, enthusiastic cohort of the previous group of learners presenting and defending significant projects, with many other learners walking in and out and taking part in the proceedings in a very friendly, constructive atmosphere made a huge difference.

We always finished the day reinforcing the ideas of waka, whānau, and collaborative knowledge building according to the mohiotanga and tukana learning values (Rangatahi Tū Rangatira, 2020).

\section{During the Term}

In the institution, we had three staff with a combined experience of more than 100 years in industry and academia. We had four cohorts of learners in three physical classrooms. It was a one-year Level 7 programme. We had four nominal courses of 30 credits each and a capstone project worth 60 credits as key components of project-based learning.

Project-based learning which emerged at the beginning of the last century now acquires a new way of implementation with the advancement of digital technologies. Project-based learning enables students to acquire knowledge and develop core competences while learning curriculum content (Moura, 2019).

Two of the four 30-credit courses were offered alternatively. The other two were optional and any learner could opt to do one of these optional courses in any of the first two terms. Only learners with prior knowledge in a certain area could choose the other optional course. The capstone project was offered over two terms.

There were three rooms, three staff, and several options for learners to choose from. This would not have been possible if we followed the traditional lecture/tutorial model. We treated each learner as an individual; some had as many as 15 years' experience in the relevant industry, others were absolute beginners, with minimal English language proficiency and very little confidence. Some, especially those with prior experience had unique interests and wanted to extend their knowledge way beyond what the programme offered; others joined with the idea of just getting a qualification only as a pathway to a visa and residency.

\section{Assessments}

This is where assessment design became critical. Assessment is not only about measuring what students know and don't know. Assessment is a tool to evaluate learners' subject based knowledge and skill as well as their transferrable skills such as critical thinking, problem-solving, team-work and communication skills (Nightingale et al., 1996). Since learners were given the option to choose courses other than those scheduled for the majority of students, in some terms we had more 'classes.' What we did was write assessments to cover the learning outcomes comprehensively, but generic enough that they can be used every term. The one thing we did religiously was that at the end of each term, we reviewed each assessment and tweaked these based on our experience, learner performance and feedback.

We did not assess the ability of learners to paraphrase what they learned. We assessed their understanding by looking at how they applied what they learned to solve one or more problems in traditional, or innovative ways. Paraphrasing a well written sentence or paragraph can be time consuming and, in most cases, less meaningful than the application of the knowledge to solve a problem. 


\section{How did our Learners Learn?}

One NZQA panel member asked, "If you don't teach, what do you do in the class?" They didn't believe my 25-minute-long answer until they met with our learners.

\section{We created highly collaborative learning environments}

Learning always occurs and cannot be separated from a social context according to Vygotsky (1978). Consequently, to create a collaborative community of learning we promoted collaboration and eliminated competition (no Bell curves used to standardise grades); eliminated the stress of, and the mindless cramming before, written theory examinations; and introduced and reinforced the idea that when one helps another solve a problem they both learn.

\section{We helped our learners become authentic life-long learners}

Authentic learning is defined as learning that is seamlessly integrated or implanted into meaningful "real-life" situations (Jonassen, Howland, Marra, \& Crismond, 2008). To facilitate authentic learning, the roles of teachers vary from a resource provider and subject matter expert to learning facilitator, however a teacher can also act as a catalyst for change (lucu \& Marin, 2014). We achieved this by being life-long learners ourselves, often sharing what we learnt that day, that week, that year and even decades earlier, and what we were learning at that point in time and planning to learn in the future. We emphasised the importance of learning and becoming life-long learners; we shared our experiences as learners, learning things like stretching, Highland fling, yoga, meditation and Bhangra dance in class, and making learning an enjoyable activity.

\section{We made the learning personalised and enjoyable}

As mentioned earlier, new learners got to see what learners in the previous cohort completed during their first semester. This gave them a good starting point to think about what they might want to do as a project in meeting the learning outcomes of their first course. They only did one course of 30 credits each term and many senior learners voluntarily mentored and helped new learners find their way in a new environment both in the classroom and often in the outside world. Learners gain better understanding of cultural values in Aotearoa / New Zealand including tuakana/teina where more seniors look after the junior rangatahi. During the first few weeks each learner negotiated a project with the faculty, a project that interested them, that met the learning outcomes, and was within their ability. As they did projects that they wanted to do, not some fictitious project the lecturer came up with and spent hours writing, the motivation to complete the project was high.

\section{We supported them as and when required}

All learners were expected to, and did spend 20 hours per week in class. Timetabling was a breeze: Mondays and Tuesdays 8:00 a.m. to 5:00 p.m., Wednesdays 8:00 a.m. to 12:00 noon, totalling 20 hours per week. Note this met the NZQA/INZ requirements. The faculty did not sit in separate offices but spent most of every working day in the classrooms. Some learners also spent most days and/or several evenings in the classrooms with many others popping in and interacting with other learners and staff. The focus was on learning, caring, sharing, and supporting each other - waka, whānau and collaborative knowledge building.

\section{How did they Learn the Discipline-Specific Content?}

We used a range of online resources. Each learner picked the best resources that suited their learning styles. As learners worked on their projects, they found the knowledge they needed to progress in their project and used that knowledge - a just-in-time method of learning. On Mondays, Tuesdays and Wednesdays at 10:00 a.m. and on Mondays and Tuesdays at 3:00 p.m. we did a short stretch session, a yoga session, a meditation session or a dance lesson. Straight after these sessions a few learners would update the faculty and the other learners on their 
learning, and the best resources they had found with others joining the conversation and building knowledge. We even encouraged learners to deliberately make "mistakes" and celebrated making mistakes and learning from these mistakes. Faculty made sure that the learners were making adequate progress towards meeting the learning outcomes.

\section{Why Most of our Learners did not try to Cheat}

From the above it is clear that faculty, supported by continuing learners, consciously and deliberately created a trusting, caring whānau relationship with new learners. As learners see no one else was trying to cheat, and everyone enjoying the learning and making progress, they also wanted to make progress themselves. No learner from earlier cohorts whispered in their ears that it was easy to pass the course by copying some old assignments.

\section{How did we Catch the Few that Tried to Cheat?}

We had 121 learners complete about 500 courses. Of these, we only had six instances of cheating. In every one of these six cases, the lack of progress of these learners was abundantly clear throughout the term, not only to the faculty but also to all other learners, especially during the mini presentations. Regardless, they were brazen enough to submit work that was not completed by them.

We video recorded all final presentations and defence. During the defence, it is not possible to answer questions on the work submitted unless they completed the submitted work themselves. What surprised us was that two of these learners had been tutors themselves, elsewhere. Both appealed and complained making several unfounded allegations. All we had to do was to provide, to the appeals and complaints committee, our response along with the recordings of the final presentations and defence, as evidence.

\section{Marking and Moderation}

We made the tedious task of marking, the only task that many academics don't like doing, a pleasant experience for staff and a learning experience for all. We also finished marking in a very short time. Every term, graduating learners' grades were ready, on the Monday following the end of term, all were moderated, internally, and externally and, signed off.

Learners loved the whole process too. There was very little stress if any, no cramming, they each had a cool project to show prospective employers, and knew if they passed or failed on the same day of their final assessment.

\section{How did we do it?}

Each learner did several mini presentations during the term. These presentations not only helped our mostly international learners gain confidence in listening, presenting, asking and answering questions, but also enabled faculty to monitor their progress and proactively mentor and guide them towards successful completion.

One week before the end of term, each learner did a trial presentation and defence. During these sessions, other learners and faculty gave feedback.

On the last day of the penultimate week of each term, learners submitted reports that included extensive individual reflections on what they learned during the term. Faculty had a week to read through, make notes and plan what they wanted to ask during the final defence.

Learners did their final presentations and defence to an audience consisting of all members of the faculty, one or more external moderators, industry sponsors, all other learners, interested staff from the rest of the institution, and friends and family. Even members of the public were welcomed. 
At the end of each presentation and defence the examiners independently assigned grades to each learner, following the marking rubric and then compared the grades before assigning a final grade. At the end of the day, faculty and the external moderator deliberated and adjusted the grades if necessary, and the external moderators' comments recorded for making improvements the following term. All paperwork, including internal and external moderation was signed off, learner reports, supporting documents and video recordings archived.

Although the faculty did a lot of work on the day of final presentations and defence, the faculty and all learners looked forward to the day which had a different significance for the different groups: presenting learners excited to complete their courses or qualification; other learners to learn from these sessions; faculty, happy to see learners complete courses and qualifications; industry, to see their projects completed and able to identify suitable candidates and offer jobs; family and friends, able to witness learners complete; marketing staff able to see the learners whom they recruited complete and also to capture the stories and use to promote the programme to potential learners.

\section{PART 2: AUTHOR 2}

\section{Do Things Differ at OPAIC?}

As the second author of this paper and a head of department and principal lecturer, I would like to reflect on my experience at OPAIC and whether our current practice is different from the first author's experience. We are currently offering a bachelor's degree and a graduate diploma in information technology at OPAIC. The delivery is based on an experiential learning approach through which opportunities are created for learners to build upon skills as they progress through the programme. The experiential approach allows learners to respond to their needs by taking part in a variety of activities to reveal gaps in skills or understanding. With this approach, learners encounter new experiences, reflect on their observations, solve problems with proposing new ideas and apply their idea to a real-world problem (Kolb, 1984). We actively provide formative feedback to learners to have an informed progress in the development of specific skills. Every learner creates an individual evidence-based portfolio to enhance own employability outcomes (Otago Polytechnic, 2013).

We provide a multi-faceted and incremental approach at different stages of the learners' journey. An incremental learning framework takes learners from structured experience to self-determination. At the beginning, the aim is to recognise prior knowledge and experience and make best use of learners' prior learning and help learners create new knowledge.

In the midway points throughout the qualification, learners are provided with different opportunities to work on problem solving skills within a team including their teacher. This is to generate knowledge, reposition, and apply knowledge through collaborative and inquiry-based problem solving.

The last stage of the programme helps learners develop skills through project-based learning. They build competence to act in various real-life situations. Most Level 7 courses involve project-based learning through which learners find a real-life problem or a business gap and apply their knowledge and skills to build a solution in the context of the course subject. The majority of learners who carry out their final project are involved in realworld projects with industry and/or for industry. The project-based learning is personalised for learners to make the best use of and maintain their motivation and engagement, and to cope with the challenges throughout the project term. They directly work with industry partners / clients and improve their technical as well as soft skills through regular communications with the project clients.

Moodle, as a content management system, is effectively used for all subjects to supply course materials and, as a platform to keep the communication line with learners active. The delivery content including meaningful 
and engaging activities is created by lecturers with the aim of preparing learners to successfully complete their assignments and project work. Progressive self-assessment is a key part of our team's practice to maintain consistency, quality and performance across the delivery and development processes.

The first author joined OPAIC as a Senior Lecturer several months ago. We are now combining the best elements from our prior experiences to evolve a highly learner-centred mode of facilitating learning.

\section{PART 3: RESULTS}

Merging the best practices from both author's experiences, we have some great results at OPAIC.

I. Focus group summary Block I, 2020 for the Programming I Course (Entire course delivered face-to-face):

They enjoy their classes and they think what they are learning is current.

They know what is expected of them and they are confident in what they have to do in order to be successful in their course.

They enjoy their lecturer's style of teaching and they say that he doesn't rush and he teaches to their needs and builds on what they already know.

They are happy with the feedback they get. He provides same day feedback and gives clear formative feedback which they can use to improve.

2. Focus group summary Block 2, 2020 for the Web 2 Programming Course (Entire course delivered online, due to COVID-19):

The lectures are going fine and they are used to the teaching style of the lecturer because they have had him before.

They find the checkpoints helpful and useful.

They like how all the materials are supplied online.

They understand their assessments and know what is expected of them.

They think the time spent online with the lecturer is a good amount.

They like that they have chances to discuss with each other and clarify with the lecturer.

3. In Block 3, 2020 we delivered a course titled, "Developing Flexible IT courses". The following is an unedited extract from work submitted by one of the students in this course.

"The type I decided to teach this course, I prefer with my two lecturers delivering style one is Kathiravelu Ganeshan and the other is Farhad Mehdipour. From Mr. Ganeshan, I learn how to be friendly with students and to do more practical things related to the course and to relate your course with daily life learnings, and from Mr. Farhad, I learn how to deliver your course through presentation and the activities after presentations. So, I would like to combine both learning styles for this course delivery." 


\section{CONCLUSION}

Our methods evolved, over time, based on our own experiences. Our focus is on helping learners become independent critical thinkers, capable of positive contribution towards solving the problems facing the world. Our thinking was probably influenced by the thinking of Socrates (470-399 BC). Our methods may even be considered adaptations of the Socratic Method in our domain of activity, the fast-changing and exciting world of computing, robotics, artificial intelligence and machine learning.

We note that similar methods have been used by others. For example, the following is from a 1998 publication of the University of Chicago Law School (Garrett, 1998).

We could lecture students about legal reasoning, but those of us who use the Socratic Method prefer to foster as much active learning as possible. Just as a professor who immediately answers her students' questions loses an opportunity to help them discover the answers on their own, the professor who dispenses legal principles in classroom soliloquies will reduce students' opportunities to engage in independent critical thinking that can lead them to a deeper understanding.

We believe that learning is not sitting some people in a lecture theatre and teaching them what the lecturer knows, copied, or even memorised without understanding. The world and industry need people capable of thinking way outside their bubbles, working with people from many disciplines, coming up with new ideas, and solving the many problems we face as humans.

We believe that if disciplines as varied as law and computing can use similar methods, these probably have uses in other disciplines too.

We are aware that several schools in New Zealand and around the world also use similar methods. These include Albany Senior High School and Ormiston College in Auckland, Agora School in Roermond, Netherlands and several Sri Aurobindo Schools in Pondicherry, India.

The home page of Sri Aurobindo International School has the following quote:

It is not for our family, it is not to secure a good position, it is not to earn money, it is not to obtain a diploma that we study. We study to learn, to know, to understand the world and for the sake of the joy that it gives us.

Sri Aurobindo (1872-1950) laid the foundation for this line of thinking and started the "experiment" in education in the early nineties (Saini, 2017).

Another quite similar, probably even more fascinating, way of facilitating learning with no classes, no classrooms and no curriculum can be found at Agora School, Roermond, the Netherlands (Webb, 2019).

Although, we evolved our own ways of facilitating learning based on our own experiences, challenging contemporary practices such as the traditional lecture/tutorial model and ditching Bloom's Taxonomy (Ganeshan, 2019) and theory examinations, we note that similar ways of facilitation of learning have been in use for at least 2500 years.

We are hoping that in the near future we will find ways of doing something similar to what is being done at Agora School, with students given so much flexibility that there are no departments, disciplines and year-levels, only collaborative learning environments, face-to-face and online, in which students learn what they want to learn, in their own time, at their own pace, supported by teams of staff who themselves are life-long, passionate learners. 


\section{AN OPEN INVITATION}

Readers interested in finding out more are encouraged to drop in announced or unannounced into any of our classes. Those outside Auckland can Zoom into any of our classes, anytime - no need for prior notice. Video recordings of project presentations and defence are also available for viewing.

Kathiravelu Ganeshan has extensive experience teaching at universities, polytechnics and private colleges in Australia, New Zealand, Singapore, Sri Lanka, and the USA. He has more than sixty publications, including five books. He enjoys learning and helping others become life-long learners. "Learning should be fun, not a chore."

(10) https://orcid.org/0000-0003-2620-4784

Dr Farhad Mehdipour has 20 years' academic and research and development experience in Japan and New Zealand. He has initiated and led several interdisciplinary research and development projects and has published around 100 peer-reviewed articles. He is currently a head of department (Information Technology) and a principal lecturer at Otago Polytechnic Auckland International Campus.

\section{REFERENCES}

Ganeshan, K. (2019). Education 2020: Time to Abandon Bloom's Taxonomy. Independently published.

Garrett, E. (1998). The Socratic Method. The Law School, The University of Chicago. Retrieved from

https://www.law.uchicago.edu/socratic-method

lucu, R. B, \& Marin, E. (2014). Authentic Learning in Adult Education. Procedia - Social and Behavioral Sciences, 142, 4I0-4I5. https://doi.org/10.1016/j.sbspro.2014.07.702

Jonassen, D., Howland, J., Marra, R. M., \& Crismond, D. (2008). Meaningful learning with technology (3rd ed.). Upper Saddle River: Pearson Education.

Kolb, D. A. (1984). Experiential learning: Experience as the source of learning and development (Vol. I). Englewood Cliffs, NJ: Prentice-Hall.

Moura, A. (2019, November 06). What if Education happened everywhere and anytime? Inspire Education Community. Retrieved from https://inspire.jpik.com/what-if-education-happened-everywhere-and-anytime

Nightingale, P., Te Wiata, I., Toohey, S., Ryan, G., Hughes, C., \& Magin, D. (1996). Assessing learning in universities. Sydney: University of New South Wales Press.

Otago Polytechnic. (2013). Otago Polytechnic Learning and Teaching Strategic Framework. Retrieved from https://www.op.ac.nz/ assets/PDFs/2013-Strategic-Goals/a3ca8b9c13/2013-OP-Learning-Teaching-Strategic-Framework-FINAL.pdf

Rangatahi Tū Rangatira. (2020). Tikanga Maori Values. Retrieved from https://www.r2r.org.nz/maori-health/tikanga-maori-values. html

Saini, A. (2017). Educational philosophy of Sri Aurobindo Ghosh. Recent Researches in Social Sciences and Humanities, 4(2), 4, 70-75.

Vygotsky, L. S. (1978). Mind in Society: The development of higher psychological processes. Cambridge, MA: Harvard University Press.

Webb, A. (2019, May 04). Meet the School with no classes, no classrooms and no curriculum. Pi-top: Learning by Making. Retrieved from https://medium.com/pi-top/meet-the-school-with-no-classes-no-classrooms-and-no-curriculum-7cc7be5/7cef 